\title{
Making a gender difference: Case studies of gender mainstreaming in medical education
}

\author{
P. VERDONK', Y. W. M. BENSCHOP², J. C. J. M. DE HAES ${ }^{3}$ \& A. L. M. LAGRO-JANSSEN ${ }^{4}$ \\ ${ }^{1}$ Maastricht University, ${ }^{2}$ Radboud University Nijmegen School of Management, ${ }^{3}$ Academic Medical Centre University \\ of Amsterdam, ${ }^{4}$ Radboud University Nijmegen Medical Centre, The Netherlands
}

\begin{abstract}
Background: Curricula are accommodated to the interests of new groups after pressure from social movements outside institutions. A Dutch national project to integrate gender-gender mainstreaming (GM) - in all medical curricula started in 2002 and finished in 2005. GM is a long-term strategy which aims at eliminating gender bias in existing routines for which involvement of regular actors within the organization is required.

Aims: In this paper, the challenges of GM in medical education are discussed. Three case studies of medical schools are presented to identify key issues in the change process.

Method: Steps taken in the national project included the evaluation of a local project, establishing a digital knowledge centre with education material, involving stakeholders and building political support within the schools and national bodies, screening education material and negotiating recommendations with course organizers, and evaluating the project with education directors and change agents. Data are gathered from interviews and document analysis.

Results: Factors playing a role are distinguished at three levels: (1) policy level, such as political support and widespread communication of this support; (2) organizational level such as a problem-based curricula and procedures for curriculum development and evaluation; and (3) faculty's openness towards change in general and towards feminist influences in particular, and change agents' position as well as personal and communicative skills.

Conclusions: Successful GM in medical education is both a matter of strategy as well as how such strategy is received in medical schools. A time-consuming strategy could overcome resistance as well as dilemmas inherent in GM. More female teachers than male teachers were openly accepting. However, women were situated in less visible and less powerful positions. Hence, GM is accelerated by alliances between women aiming for change and senior (male) faculty leadership.
\end{abstract}

\section{Introduction}

A large body of evidence was collected in the last two decades to bridge our knowledge gap concerning men's and women's health and the meaning of gender for health and illness. Gender differences exist in the background of health, the presentation of health complaints, consequences, treatment, and prevention of disease (Doyal 1995; Lagro-Janssen \& Noordenbos 1997; Lorber \& Moore 2002; Courtenay 2003). Besides biological differences, social definitions of maleness and femaleness and gender relations impact on health inequalities (Verdonk et al. 2006). Equity in health outcomes is an unachievable outcome due to the different biological constitutions of men and women, but avoidable inequalities in life expectancy or morbidity can be reduced (e.g. Doyal 2000). Also, gender bias still exists in medicine. By educating future doctors, medical education provides specific opportunities to promote gender awareness in medicine (Verdonk et al. 2008a). Therefore, integrating a gender perspective in medical education or 'gender mainstreaming' (GM) is important. In three case studies, we identify key issues in the process of GM in medical education.

\section{Practice points}

- Medical education has been slow to integrate the growing body of knowledge in gender health issues in facets of education like text books and educational material.

- Health is a critical area of concern in which action is needed to achieve gender equity.

- Gender mainstreaming (GM) aims at eliminating gender bias in existing routines for which involvement of regular actors within the organization is required.

- Facilitators are education material, guidance by experts, political support, open-minded faculty and a communicative change agent; barriers are a biomedically oriented and traditional curriculum.

- These factors together establish an organizational climate in which GM can - or cannot - take place.

GM is directed at gender (in)equality in organizations and the existence of systematically collected, analysed, and published statistics and evidence for gender differences is indispensable for achieving this (Rees 2001; Council of Europe 2004).

Correspondence: P. Verdonk, PhD, Maastricht University, Fac. HML, Dpt. Social Medicine, PO Box 616, 6200 MD Maastricht, The Netherlands. Tel: 31433881713 ; fax: 31433690960 ; email: petra.verdonk@socmed.unimaas.nl/petraverdonk@chello.nl 
GM aims at eliminating gender bias in existing routines for which involvement of regular actors within the organization is required (Stevens \& Van Lamoen 2001; WHO 2002; Council of Europe 2004; Benschop \& Verloo 2006; Lombardo \& Meier 2006; Morley 2007). Among general principles of GM are a drive to social justice and respect for diversity (Stevens \& Van Lamoen 2001). It focuses on systems and structures by 'the systematic integration of equal opportunities for women and men into organizational structure and culture, into policies, programmes, and projects, into ways of seeing and doing' (Rees 2001, p. 246). Nevertheless, the incorporation of gender into policies, programmes, and projects has not been studied as thoroughly as gender (in)equality in career opportunities. For instance in the World Health Organization's 'Gender Policy', rationales are offered for integrating a gender perspective in their work (WHO 2002). Health is a critical area of concern in which action is needed to achieve gender equity, and education is an important target because it transfers norms, knowledge, and skills (Zimmerman \& Hill 2000; Council of Europe 2004). Education systems should counterbalance existing gender hierarchies in all elements: part of higher education's mission is to promote gender studies as a field of knowledge that is strategic for the transformation of higher education and society (UNESCO 1998).

A demographic explanation of curriculum transformation sees curricular change as a response to changes in the student population (Slaughter 1997). However, despite evidence on gender health issues and the increasing number of women as students and faculty, medical education has hardly integrated gender health issues in facets of education like text books and educational material (Alexanderson et al. 1998; Verdonk et al. 2005, 2008a; Dijkstra et al. 2008). Institutions make little effort to accommodate curricula to the interests of new groups (Slaughter 1997). Instead, social movement theory states that curricula change because of the pressure of movements originating outside the institutions and by faculty who participated in the women's movement (Blackmore et al. 1996; Slaughter 1997; Morley 2007). The analysis that gender informs life including health was developed first outside the institutions, and moved only into it after demands and protests from the women's movement (Slaughter 1997; Taylor 1998). More specifically, feminism pointed to gender bias in the production of knowledge in general and of medical knowledge in particular and asserted that knowledge is value-laden (Acker 1987; Tisdell 1995; Slaugher 1997; Verdonk et al. 2008a).

In medical education, GM is both a matter of content and process and does not consist of linear phases between research, policy production, and implementation (Blackmore et al. 1996). In 1998 in the Netherlands, we performed a pilot study to establish how new knowledge regarding gender is presented in the Radboud University Nijmegen Medical Centre medical curriculum (Verdonk et al. 2005). Educational material was screened for content, context (i.e., the context in which male and female patients are presented) and language (i.e., is the student always presented as male) (Zelek et al. 1997). In order to evaluate the curriculum, a list of objectives was made based on the literature and expert opinion to denote the successful implementation of gender health
Table 1. Objectives to denote the successful implementation of gender issues in medical curricula.

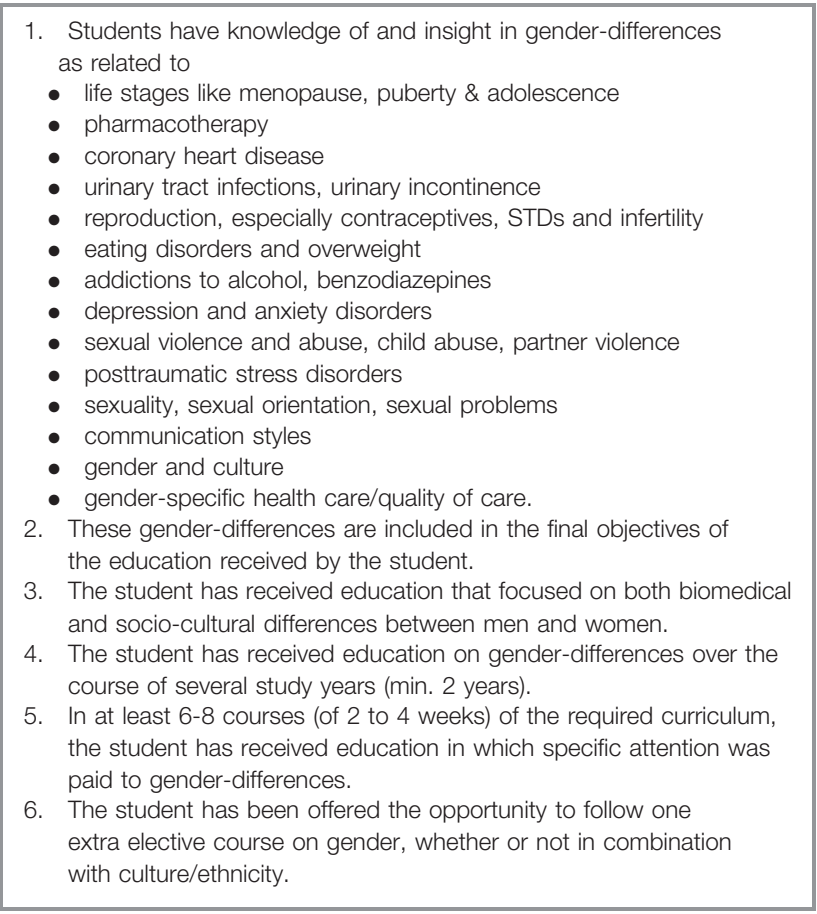

issues (Table 1); e.g. based on Magrane \& McIntyre-Seltman (1996), Lagro-Janssen \& Noordenbos (1997), Zelek et al. (1997), Searle (1998), Beck Weiss \& Levison (2000), Doyal (2000), Krasnoff (2000), Bickel (2001), Östlin et al. (2001), Rinto \& Adams Hillard (2002) and Lorber \& Moore (2002).

The topics involve relevant biomedical as well as psychosocial and cultural gender gender-related aspects. They relate to major medical disciplines: internal medicine/cardiology (e.g. coronary heart disease), psychiatry (e.g. major depression and substance abuse), and gynecology/urology (e.g. reproductive health). Furthermore, evidence was available for biological and sociocultural gender differences which is essential for reviewing and evaluating curricula in medical schools. Besides disaggregated data and knowledge, other GM tools that apply to integrating gender in medical education are political support, resources (time and money), monitoring and evaluation mechanisms, awareness-raising and training in faculty and staff, and building ownership through integrating gender into line management systems (Beck Weiss et al. 2000; Council of Europe 2004; LaBare 1993; Rees 2001; Stevens \& Van Lamoen 2001; Verdonk et al. 2005).

In 2002, the Netherlands Organization for Health Research and Development funded a national project to integrate gender health issues in all eight medical curricula (commissioned by the Dutch Ministry of Health). The project sought to introduce a gender perspective into existing policies and routines and therefore holds a more 'integrationist' view of GM (Morley 2007).

Three case studies illustrate key issues that play a role in the medical education GM project. The case studies are chosen for their organizational and educational contrast as well as different approaches towards the project. The cases are presented anonymously to protect the privacy of participants. 


\section{Methods}

The Nijmegen Professor and head of the department of Women's Studies in Medicine was appointed as a project leader which secured the knowledge base of GM (Stevens \& Van Lamoen 2001; Morley 2007). Furthermore, two project members were attracted. Stakeholders were involved by participation in a steering group: representatives of the funding organization, change agents and education directors provided feedback and input (Tisdell 1995; Stevens \& Van Lamoen 2001; Council of Europe 2004;). Finally, in Review Committee audits the Dutch and Flanders' medical schools' pursuit of nationally established objectives in curricula is appraised every five years. In 2002, the Dutch committee round coincided with the GM project. At our request, the Review Committee asked the schools how and where gender issues were addressed in medical curricula. The legitimization of curriculum change efforts by the institution and other organizations are important (Tisdell 1995; Blackmore et al. 1996; Slaughter 1997).

The GM project can be defined as an action research project to indicate the use of a combination of research and intervention as well as active involvement of faculty within the schools (Wadsworth 1998; Stevens \& Van Lamoen 2001). By discussing findings outlined in screening reports, a personal approach was used to gain support for GM. Data were gathered from (1) interviews and (2) document analysis. Reports evolving from document analysis were used for intervention. The national project was conducted in several steps which are discussed below. We evaluated the project in 2005 with 18 change agents and faculty leaders of 7 schools by interviewing them. Interviews - lasting from 15 to 50 minutes were structured by an interview guide and hand-coded for factors that played a role in the GM process. Key factors have been thoroughly discussed (researcher triangulation). Notes of meetings during the project were used to further validate the key factors and underscore our arguments (method triangulation).

First, we describe the steps taken in the national project. In the results section, the three case studies are described and key issues are analysed.

\section{The national project in five steps}

In the initial step in April 2002, we identified how gender was integrated in the Nijmegen curriculum four years after the local pilot project was done. In 2002, we screened the educational material anew and held interviews with course organizers (Verdonk et al. 2005). Gender health issues had increasingly been brought to the attention of students. During the interviews, new ideas were put forward and new agreements were made. Among factors contributing to integrating gender were: (1) concrete and directly executable content-oriented recommendations; (2) motivated course organizers; (3) presence of a change agent in the school; (4) involvement of course organizers in decision-making, and; (5) the provision of practical support. These factors were taken into consideration in the national project (Verdonk et al. 2005).

e196
Secondly, nation-wide interventions were developed. Curricula can be transformed effectively through faculty development: changing course content and perspective changes pedagogy and goals (LaBare 1993). This is especially important since the knowledge base of gender is frequently under-estimated (Morley 2007). New initiatives must present knowledge relevant to marginalized groups (Tisdell 1995). We therefore set up a digital knowledge centre (www.kenniscentrumSDMO.nl) from which teachers and course organizers could retrieve gender sensitive educational material, such as case-based study assignments, presentations, or exams. Digital newsletters were disseminated to inform participants about newly developed or acquired educational material. A train-the-trainer course was offered, and two invitational conferences - one international - were organized about implementation strategies and structural embedding of gender issues in medical education.

In the third step, we established political support in policy makers (Tisdell 1995; Benschop \& Verloo 2006). A baseline assessment was needed to expose omissions in teachings about gender in medical schools as well as opportunities to integrate gender in specific courses (Verdonk et al. 2006). Study guides of seven medical schools - the pilot project school was excluded - were scanned. For each medical school, a screening report was written and recommendations to incorporate gender issues into specific courses were made. Conclusions were discussed with deans and directors of medical schools as well as other policymakers, such as education consultants or curriculum committee chairs, to create commitment towards curricular accommodations (Tisdell 1995; Slaughter 1997; Stevens \& Van Lamoen 2001). The faculty leaders - the directors or other key persons of the institute - were approached by mail and after a few weeks by telephone to make an appointment. All agreed to meet with us. We considered this step successful if they acknowledged the gaps in medical education and if a local strategy to integrate gender was set out (Verdonk et al. 2006).

In the fourth step, we first screened existing actual educational material for content, context and language (Zelek et al. 1997) and presented practical recommendations in reports. Secondly, these reports were discussed and negotiated with course organizers (Tisdell 1995; Slaughter 1997; Stevens \& Van Lamoen 2001). We also discussed opportunities for electives.

In the fifth step we evaluated the project with change agents and faculty leaders (Stevens \& Van Lamoen 2001; Verdonk et al. 2008b).

\section{Results}

\section{The case studies}

Case study $1 \mathrm{X}$-MC. At the X-MC, a biomedical research tradition existed, the curriculum was organized along disciplinary lines, and there was no supporting education institute. Curriculum reforms started in 1999-2000 and focused on case-based learning which had caused resistance among faculty. In January 2003, we arranged a first meeting with the curriculum reform co-ordinator. The co-ordinator 
acknowledged that knowledge about biological sex differences were lacking in the curriculum despite the biomedical curricular orientation. After the meeting, education material of required courses was analyzed and the educational committee and the committee for curriculum reform were informed.

In March 2003, a strategy to integrate gender was set out with the curriculum reform co-ordinator who was the local change agent, the 3rd year co-ordinator and a manager. Committees and the dean were informed anew and gave their consent.

Course screening reports were first discussed with the change agent. In October 2003, two group meetings with course organizers were planned. Not all invited persons came. Group dynamics prevented discussing gender issues: high status faculty openly expressed their opposition towards the project. These meetings proved a backlash for the project although we screened educational material in a second round. No further meetings took place.

In March 2004, the head of the department of primary care and the dean organized a seminar about gender differences around International Women's Day without any linkage to our project. Through the schools' newsletter, we informed local teachers and exposed the dean's interest in gender health issues.

A second trail was followed with the electives' co-ordinator. The school was looking for a new course on sexuality issues in which the department for psychosomatic gynaecology and sexology took an interest. In a meeting in October 2003, the knowledge centre's supportive means for educational material were discussed and a course was developed. A first elective Sexology was successfully given in the Spring of 2005. The course organizer presented the course at our second Invitational Conference.

In evaluative interviews, policymakers within the school admitted that political commitment had been low, that no consensus had existed at policy level, that the integration of gender had failed, that the project's relevance was widely questioned, and that diversity issues - especially cultural/ ethnic issues - were considered more important.

A new committee on integrating diversity issues was established after the project ended in 2005 under the leadership of the department of Primary Health Care. In the Spring of 2006, our earlier recommendations to integrate gender issues were sent anew to this committee at their request. The committee planned a new round of discussing these recommendations (extended with new recommendations regarding cultural/ethnic issues) with course organizers.

Case study 2 Y-MC. At Y-MC, educationalists offer support in organizing, planning, writing and evaluating the curriculum and in developing exams; they also offer teacher courses and contribute to education policy. In the past, the Y-MC was known for its biomedical orientation. Major curriculum reforms that started after the Review Committee's critical comments in 1997 were still ongoing.

In a first meeting in 2003, the education director stated that the project might create resistance and referred to faculty's downplaying of the importance of interculturalisation earlier. Nevertheless, the gender-specific educational material presented clarified the relevance of integrating gender to the education director and we screened Y-MC's educational material. A group meeting with all course organizers was planned.

No follow-up was given to the meeting due to delay within the school. In 2004, a new education director was installed and a new meeting was arranged in February 2004 with the new director and an educationalist who acted as change agent. Both admitted that they had been reluctant to participate but again, the gender-specific educational material had convinced them.

The education director discussed the project with the course organizers in a regular meeting. Next, the change agent arranged meetings with course organizers to discuss screening reports and raise awareness. In year four, which was under construction, course organizers wanted to integrate gender as well as cultural/ethnic issues. Recommendations to integrate both topics in their outlines were offered. For the other courses, screening reports were sent to organizers before the meetings, which were attended by the project member, the change agent and occasionally another educationalists assigned to the specific courses. We emphasized that the screening report contained recommendations open for discussion. Most recommendations were well taken, but some were not considered suitable. Notes were taken at all meetings and presented for agreement to the educationalist and the course organizer. Gender was kept on the agenda by the change agent, who was enthusiastic and was allowed to devote time to the project.

The school already aimed for an interdisciplinary curriculum and some of the gender-specific objectives were already integrated in the new curriculum. The evaluation of gender health issues is officially integrated in evaluation procedures and educationalists and teachers are responsible for the follow-up of recommendations. The project is widely communicated in meetings and digital newsletters for teachers and course organizers. The education institute has no say in the organisation of electives and no elective is developed. In 2004, one of the educationalists participated in the trainers' course. Progress with GM was presented at our second Invitational Conference.

In 2005, a new education director was hired. In April 2005, official policy for the Y-MC's responsibility towards integrating gender as well as other aspects for diversity was formulated.

Case study 3 Z-MC. The Z-MC aimed towards an interdisciplinary curriculum in which psychosocial issues were also addressed. However, the actual curriculum still mainly focused on biomedical issues. Ethics was also considered important to guide future doctors in decision-making. In a first meeting in 2002, the aims of the project were clear and relevant to the education director. Information about the project was disseminated to the chair of the curriculum reform committee and the curriculum co-ordinator. However, the project was severely delayed due to personnel changes.

In 2003, we met the education director anew and in August, integrating gender was discussed with the new chair of the curriculum reform committee, the education director, and several course organizers. Jointly, a strategy was set out. A professor in gynecology and sexology, also a course 
organizer, accepted change agency for the GM project and kept an overview of recommendations to prevent overlap in the curriculum.

Educational material of some courses of the newly developed first year as well as outlines for year two and three were screened. Proposals for gender-specific elective projects were also offered. Educational material of the Nijmegen elective about gender, sexuality and ethnicity was integrated in the change agents' own third year required course. Two meetings took place with course organizers of year one. The screening report with recommendations to integrate gender in year two and three was sent by email to the change agent. In the meantime, the change agent had become co-ordinator of the bachelor phase and of the GM project within this phase.

The education director as well as the change agent and the chair of the curriculum reform group visited our first Invitational Conference. In 2004, the change agent and two teachers participated in the train-the-trainer course, and the change agent presented results of an evaluation round as regards the integration of recommendations. Gender is integrated in official education policy and new goals are set to integrate gender issues in the master phase of the curriculum.

\section{Key issues in the change process}

Strategies and results differed in the schools due to organisational culture and structure, the presence of sufficient resources (time), political support, (dis)agreement as regards integrating gender, andother factors. Everywhere in the Netherlands, curriculum reforms were taking place or about to take place. Key issues in the change process can be distinguished at three levels: (1) policy level; (2) organisational level; and (3) the cultural level. Table 2 sums up key issues in the process of GM.

At the policy level, outspokenness of education directors' and deans' support, consensus for instance in curriculum committees, and the communication of political support was important. Open support diminished resistance especially in high status faculty and motivated the change agent. Support by

\section{Table 2. Key issues in GM in medical education.}

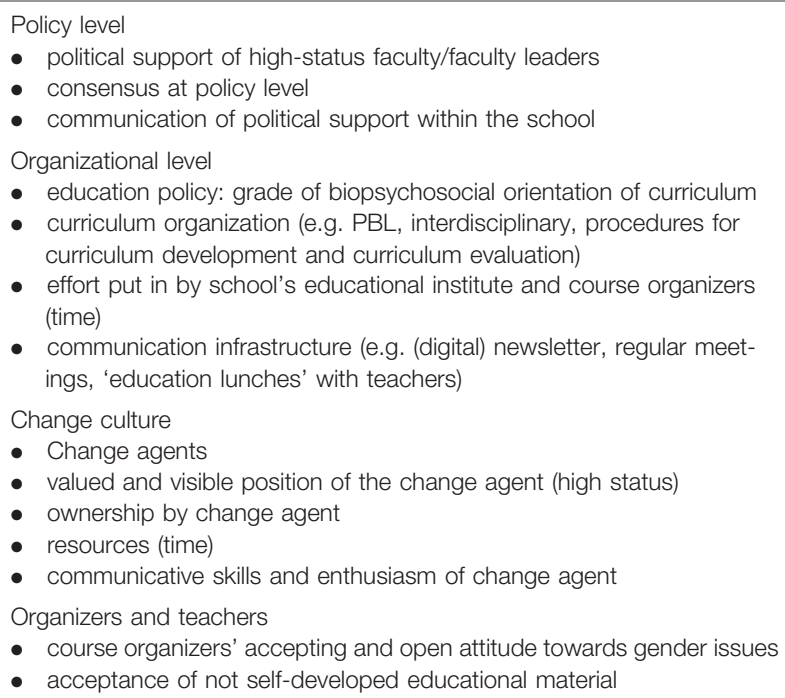

- valued and visible position of the change agent (high status)

- ownership by change agent

- resources (time)

- communicative skills and enthusiasm of change agent

Organizers and teachers

- course organizers' accepting and open attitude towards gender issues

- acceptance of not self-developed educational material

faculty leaders legitimized spending time and organizational resources on the project.

A well-organised education institute, educationalists' interference with the curriculum and the recognition of interdisciplinary issues facilitated the uptake of gender health issues. They were easily integrated when policies and procedures for curriculum development and evaluation already existed. Communication structures (like digital newsletters or education lunches) were decisive to communicate the aims of the project to faculty and staff.

As regards culture, a supportive and open atmosphere was enhancing change. Outspoken acceptance of the project aims during meetings, clear appreciation of the work done and the education material offered, follow-up of agreements and practical support were markers of this supportive atmosphere. It turned out important that the change agent had a senior and well-respected - and hence, supported - position within the school, was enthusiastic, skilled in communication, put effort into the project, was determined to succeed in spite of difficulties. He/she was to have intensive contact with course organizers and teachers. The change agent stood at the crossroads of top-down and bottom-up processes, holding an intermediate position between course organizers and faculty leadership. Political support legitimized change agents' time investment in the project and upward communication of achievements to education directors motivated them vice versa.

Other factors that played a role are the National Review Committee's audit round. This Committee asked the schools how and where in their curricula gender health issues were addressed. A strong barrier for GM was a biomedical tradition and the disciplinary and traditional organization of curricula. In the absence of political support in case 1, we could only communicate aims and recommendations of the project to those already involved in gender issues and/or willing to resist current dominant ideas within the schools. This greatly limited awareness raising opportunities. Staff turnover also played a role: it obviously mattered who left the school and who was hired. In case study 3, personnel turnover severely delayed the project. However later, it accelerated the project because the change agent became co-ordinator of the bachelor phase besides being a course organizer. Thus, faculty's personal attitudes were important. GM is based on political support, needs a certain organisational structure as well as the facilitation of change culture and draws on the position and communicative skills of change agents.

Last but not least, policy makers and education directors hence, decision makers - were mainly male. Supportive teachers, educationalists and change agents were mainly (junior) female faculty: thus the request for change came mostly from women, whereas change itself depended greatly on men's willingness. Hence, alliances between (senior) men - actors usually not involved in gender issues - and women are decisive.

\section{Discussion}

This study investigates key factors in the process of gender mainstreaming (GM) in all eight Dutch medical curricula. 
GM in medical education comprises attitude change. It gains from certain conditions but also faces the usual obstacles for change in organizations (Rollinson et al. 1998). We encountered key factors for change on three levels.

Firstly, political support was exposed in for instance the commitment of education directors. These were not necessarily concerned with protecting current interests usually seen as one of the major barriers for GM in health (Levison \& Straumanis 2002; Henrich 2004). Ambivalence was however shown in education directors' as well as change agents' attitudes towards the project when they gave the project the benefit of the doubt as long as we were careful communicators (Verdonk et al. 2008b). Our study confirms that (medical) curricula do not change linearly and rationally but rather slowly in collaborative - possibly threatening - projects (Blackmore et al. 1996; Lawless et al. 2005; Slaughter 1997; Verdonk et al. 2005).

Secondly, at the organizational level, structural factors contributed to successful GM. Gender was more easily integrated in more interdisciplinary problem-based or case-based and biopsychosocial curricula than in more traditional lecture-based, disciplinary and biomedical curricula (Beck Weiss et al. 2000; Zimmerman \& Hill 2000;). Our findings confirm Risberg et al.'s (2006) statement that the domination of biomedicine contributes to resisting gender and hampers a more 'truth-like' view of life. This is however not unique to gender issues: other issues do not fit into a biomedical paradigm such as for instance pain or nutrition (e.g. Schulman 1999) and broader social subjects such as ethnicity or gay and lesbian health (e.g. Tesar \& Rovi 1998; Turbes et al. 2002).

Thirdly, cultural facilitators like openness towards change in general and gender issues in particular facilitated the uptake of gender issues. This supports findings of other authors (Levison \& Straumanis 2002; Henrich 2004). Change agents held a key position in the local schools, but needed political support, input from the project members as well as a positive response from within their school.

GM must address all levels of activity, use diverse strategies, and deal with daily, educational practice (Blackmore 1996; Verdonk et al. 2005). In our project, many obstacles for GM in medical education were already resolved by defining the objectives of a gender-specific curriculum, by offering webbased material (www.kenniscentrumSDMO.nl) as well as written education material, a teacher course, and by involving and regularly meeting with directors. This strategy - though time-consuming - is productive and results in general institutional participation especially in senior level leadership (LaBare 1993; Beck Weiss et al. 2000; Levison \& Straumanis 2002; Lawless et al. 2005).

Furthermore, Slaughter (1997) argues that curricula are negotiated beyond the institution itself. Although we tailored the project to local differences, the national character was part of our strategy. Institutions affected each other: education directors exchange and discuss their policies regularly, we presented and discussed our work-in-progress at the annual national conference on medical education, and we contributed to a wider exchange with our invitational conferences and train-the-trainer course.
Some dilemmas inherent in GM as a strategy was relevant to our project as well. The involvement of regular actors also meant that gender theory and more politically charged gender issues such as sexual violence were more difficult to integrate; content is easily lost without feminist agency and expertise (Slaughter 1997; Morley 2007). Gender health issues were easily degendered and depoliticized (Lombardo \& Meier 2006). Morley (2007) calls this dilemma the central tension between vision and strategy. The strategy to involve regular actors and hence, non-feminist advocates, not only depoliticizes gender, but easily leads to under-estimation of the GM knowledge base. Our digital knowledge centre and educational material helped to overcome this dilemma; the educational material proved important for the decision-making process at policy level but also constituted an elaborate and convincing knowledge base that offered practical support. An unresolved dilemma is that involving regular actors often implies that men and women are presented as unified, essential categories. In medicine, gender is especially associated with differences between men and women, in disease, behaviour, as well as life conditions (Risberg et al. 2008). Hence, by concentrating on difference, the GM project connected to the status quo in medical science which is a strategic move. Finding common ground may either bend attitudes towards new ways of thinking about gender differences (Anderson 2003) - without reproducing gender as mutually exclusive yet complementary categories - or it may risk obscuring similarities between the sexes and, more importantly, differences between men and between women (Morley 2007). Gender theory would address the latter essentialist presentation, but in GM there is little opportunity for theoretical reflection to rethink taken-for-granted categories and the processes that create them - surely that would risk losing common ground again (Benschop \& Verloo 2006). Despite the dilemma, gender theory is an important foundation of a gender-specific curriculum and largely, although not explicitly in our list, informs the objectives of a gender-specific curriculum.

Our results suggest that our project has certainly paved the way towards a wider view in Dutch medical education as regards background dimensions. Although some advocate GM as a long-term strategy towards equality with respect for diversity (Stevens \& Van Lamoen 2001), others are critical because in GM, gender is prioritized over other aspects such as ethnicity or sexuality, while the intersections between different background dimensions are not adequately reflected (Hankivsky 2005). The steps we took may be therefore be used to incorporate other social dimensions such as age or class in medical education, but must depart from the view that interactions between background dimensions structure the lives of women and men, including their health.

A final important question raised by GM as a methodology is whether the presence of women in science and in decisionmaking about science would make a difference (Rees 2001; Hirshbein et al. 2004). Rees wonders how aiming towards gender equality in the workforce might change organizations' routines and systems. Some claimed that female physicians are more often in favour of the equitable use of health care resources (Risberg et al. 2003; Council of Europe 2004) 
which may stimulate the medical profession toward caring for yet underserved populations (Levinson \& Lurie 2004). Although women have no monopoly on gender perspectives, curricular reform might benefit from women's input (Hirshbein et al. 2004). Since in our project, GM involved regular actors, we mostly dealt with men in higher positions. In The Netherlands, vertical sex segregation within the schools is largely intact. More women than men were openly accepting GM and recognized the problems we exposed. However, they were positioned in less visible and less powerful positions with less influence on decision-making (Riska 2001; Levison \& Straumanis 2002). Our findings confirm a gender order in medical education in which men are constituted as an interest group concerned with defence and women as an interest group concerned with change (Connell 1995, p. 82; Risberg et al. 2008). Some state that the involvement of women academics enforces relevance, effectiveness and sustainability of GM policies at universities (Stevens \& Van Lamoen 2001). However, Morley's findings (2007) also suggest that if GM is left to the women to execute, it has limited status. She concludes that feminist change agency rather than policies may have more impact on curriculum transformation. Our findings suggest that especially change agency by men has a large impact and hence, men seem to be the largest facilitators - or barriers. The uptake of gender health issues by men might also contribute positively to women's positions within the schools. It is now up to influential men to build alliances with women in their schools.

\section{Conclusion}

A GM project in medical education is a matter of strategy and of how such strategy is received. Dilemmas exist in GM, such as the tension between feminist agency and the involvement of regular actors, and the assumption that men and women are unified categories. However, these dilemmas are greatly resolved by a time-consuming, supportive and awarenessraising strategy. School factors at three levels facilitate the uptake of gender health issues. Political support, organizational structures such as procedures for curriculum development and evaluation, cultural aspects like openness towards change in general and feminist influences in particular, as well as the change agent's position and personal skills are key issues. GM is greatly accelerated by alliances between women aiming for change and senior - male - faculty leadership.

\section{Notes on contributors}

PETRA VERDONK (PhD) is a psychologist and an assistant professor Work $\&$ Health at Maastricht University.

YVONNE BENSCHOP (PhD) is a political scientist and professor Organizational Behaviour at the Nijmegan School of Management Radboud University Nijimegen.

HANNEKE DE HAES (PhD) is a psychologist and professor Medical Psychology at the Academic Medical Centre University of Amsterdam.

TOINE LAGRO-JANSSEN (PhD) is a general practitioner and professor Women's Studies Medcine at Radboud University Nijimegen Medical centre.

\section{Acknowledgements}

The study was conducted at the Radboud University Nijmegan Medical Centre by Women's Studies in Medicine, PO Box 9101-Internal postal code HAG 117, 6500 HB Nijmegan, The Netherlands.

The study was funded by the Netherlands Organization for Health Research and Development.

Declaration of interest: The authors report no conflicts of interest. The authors alone are responsible for the content and writing of the paper.

\section{References}

Acker S. 1987. Feminist theory and the study of gender and education. Int Rev Educ 33(4):419-435.

Alexanderson K, Wingren C, Rosdahl I. 1998. Gender analyses of medical textbooks on dermatology, epidemiology, occupational medicine and public health. Educ Health 11(2):151-163.

Anderson H. 2003. As if gender mattered. Feminism and change in higher education. J Higher Educ 74(3):321-336.

Beck Weiss L, Levison SP. 2000a. Tools for integrating women's health into medical education: Clinical cases and concept mapping. Acad Med 75(11):1081-1086.

Beck Weiss L, Lee S, Levison SP. 2000a. Barriers and solutions to implementing a new curriculum: Lessons from the women's health education program at MCP Hahnemann School of Medicine. J Womens Health Gender-Based Med 9(2):153-160.

Benschop YWM, Verloo M. 2006. Sisyphus' sisters. Can gender mainstreaming escape the genderedness of organizations? J Gender Studies 15(1):19-34.

Bickel J. 2001. Gender equity in undergraduate medical education: A status report. J Womens Health Gender-Based Med 10(3):261-270.

Blackmore J, Kenway J, Willis S, \& Rennie L. 1996. Feminist dilemmas: an Australian case study of a whole-school policy approach to gender reform. J Curric Stud 28(3): 253-279. DOI: 10.1080/0022027980280302.

Connell RW. 1995. The social organization of masculinity. In: Connell RW, editor. Masculinities. Cambridge: Polity Press. pp 67-86.

Council of Europe. 2004. Gender Mainstreaming. Conceptual framework, methodology and presentation of good practices. Final report of Activities of the Group of Specialists on Mainstreaming (EG-S-MS). Strasbourg: Equality Division, Directorate General of Human Rights. Retrieved 31 May, 2006, from http://www.coe.int/T/E/Human_Rights/ Equality/PDF_EG-S-MS_98_2rev_E.pdf

Courtenay WH. 2003. Key determinants of the health and well-being of men and boys. Int J Men's Health 2(1):1-30.

Dijkstra AF, Verdonk P, Lagro-Janssen ALM. 2008 Gender bias in medical textbooks. Examples from coronary heart disease, depression, alcohol abuse and pharmacology. Med Educ (in press).

Doyal L. 1995. What Makes Women Sick? Gender and the Political Economy of Health. New Jersey: Rutgers University Press.

Doyal L. 2000. Gender equity in health: debates and dilemmas. Soc Sci Med 51(6):931-939.

Hankivsky O. 2005. Gender vs. diversity mainstreaming: A preliminary examination of the role and transformative potential of feminist theory. Can J Pol Sci 38(4):977-1001.

Henrich JB. 2004. Women's health education initiatives: Why have they stalled? Aca Med 79(4):283-238.

Hirshbein LD, Fitzgerald K, Riba M. 2003. Women and teaching in academic psychiatry. Acad Psychiatry 28(4):292-298.

Krasnoff MJ. 2000. Resources for teaching about women's health. Acad Med 75(11):1087-1094

LaBare MJ. 1993. Faculty Development for Inclusive Curriculum: Principles and Processes. Paper presented at the College teaching and Learning Exchange National Conference, October 13-17, San Jose, CA.

Lagro-Janssen ALM, Noordenbos G. 1997. Sekseverschillen in ziekte en gezondheid (Gender differences in illness and health) Nijmegen: SUN. 
Lawless A, Tonkin A, Leaton T, Ozolins I. 2005. Integrating gender and culture into medical curricula: Putting principles into practice. Divers Health Social Care 2:143-149.

Levinson W, Lurie N. 2004. When most doctors are women: What lies ahead? Ann Intern Med 141(6):471-474.

Levison SP, Straumanis J. 2002. FIPSE: Changing medical education forever-Fund for the improvement of postsecondary education. Change Magazine 34(5):27.

Lombardo E, Meier P. 2006. Gender mainstreaming in the EU: Incorporating a feminist reading? Euro J Women's Studies 13(2):151-166.

Lorber J, Moore LJ. 2002. Gender and the Social Construction of Illness. 2nd ed. Oxford: Altamira Press.

Magrane DM, McIntyre-Seltman K. 1996. Women's health care issues for medical students: An education proposal Women's Health Issues 6(4):183-191.

Morley L. 2007. Sister-matic: Gender mainstreaming in higher education. Teach Higher Educ 12(5-6):607-620.

Östlin P, Danielsson M, Diderichsen F, Härenstam A, Lindberg G. 2001 Gender Inequalities in Health. A Swedish Perspective. Boston: Harvard School of Public Health.

Rees T. 2001. Mainstreaming gender equality in science in the European Union: The 'ETAN Report'. Gender Educ 13(3):243-260.

Rollinson D, Broadfield AM, Edwards DJ. 1999. Organisational Behaviour and Analysis. An Integrated Approach. New-York: Addison-Wesley.

Rinto BA, Adams Hillard PJ. 2002. Women's health in the medical school curriculum: Building support for the adoption of core competencies. Am J Obstet and Gynecol 3:S28-S29.

Risberg G, Hamberg K, Johansson EE. 2003. Gender awareness among physicians - the effect of specialty and gender. A study of teachers at a Swedish medical school. BMC Med Education 3:8.

Risberg G, Hamberg K, Johansson EE. 2006. Gender perspective in medicine: A vital part of medical scientific rationality. A useful model for comprehending structures and hierarchies within medical science. BMC Med 4:20. DOI: 10.1186/1741-7015-4-20.

Risberg G, Johansson EE, Westman G, Hamberg K. 2008. Attitudes toward and experiences of gender issues among physician teachers: A survey study conducted at a university teaching hospital in Sweden. BMC Medical Educ 8:10. DOI: 10.1186/1472-6920-8-10.

Riska E. 2001. Towards gender balance: But will women physicians have an impact on medicine? Soc Sci Med 52:179-187.

Schulman JA. 1999. Nutrition education in medical schools: Trends and implications for health educators. Med Educ Online [serial online], 4, 4. Available online at: www.med-ed-online.org/f0000015.htm (Accessed 1 May 2006).

Searle J. 1998. Introduction of a new curriculum in women's health in medical education: A framework for change. Women's Health Issues 8(6):382-388.
Slaughter S. 1997. Class, race and gender and the construction of postsecondary curricula in the United States: Social movement, professionalization and political economic theories of change. J Curric Studies 29(1):1-30.

Stevens I, Van Lamoen I. 2001. Manual on Gender Mainstreaming at Universities. 'Equal Opportunities at Universities. Towards a Gender Mainstreaming Approach'. Leuven-Apeldoorn: Garant.

Taylor V. 1998. Feminist methodology in social movements research. Qualit Sociol 21(4):357-379.

Tesar CM, Rovi SLD. 1998. Survey of curriculum on homosexuality/ bisexuality in departments of family medicine. Educ Res Methods 30:283-287.

Tisdell EJ. 1995. Creating Inclusive Adult Learning Environments: Insights from multicultural Education and Feminist Pedagogy. information series no. 361, Columbus OH: Center on Education and Training for Employment.

Turbes S, Krebs E, Axtell S. 2002. The hidden curriculum in multicultural medical education: The role of case examples. Acad Med 77:209-216.

UNESCO 1998. World Declaration on Higher Education for the Twentieth Century: Vision and Action and Framework for Priority Action for Change and Development in Higher Education (Paris, UNESCO 9 October). Retrieved 25 February, 2008, from http://www.unesco.org/ education/educprog/wche/declaration_eng.htm

Verdonk P, Mans LJL, Lagro-Janssen ALM. 2006. How is gender integrated in the curricula of Dutch medical schools? A quick-scan on gender issues as an instrument for change. Gender Educ 18(4): 399-411.

Verdonk P, Mans LJL, Lagro-Janssen ALM. 2005. Integrating gender into a basic medical curriculum. Med Educ 39(11):1118-1125.

Verdonk P, Benschop YWM, de Haes JCJM, Lagro-Janssen TLM. 2008a From gender bias to gender awareness in medical education. On-line first. Advan Health Sci Educ. DOI 10.1007/s10459-008-9100-z.

Verdonk P, Benschop YWM, de Haes JCJM, Mans LJL, Lagro-Janssen, ALM. 2008 b "Should you turn this into a complete gender matter?" Discourses on gender mainstreaming in medical education. (Submitted).

Wadsworth Y. 1998. What is participatory action research? Action Research International, Paper 2. Retrieved 10 April, 2006, from http://www.scu.edu.au/schools/gcm/ar/ari/p-ywadsworth98.html

WHO 2002. WHO Gender Policy. Integrating Gender Perspectives in the Work of WHO (Geneva, World Health Organization). Retrieved 17 May, 2006, from http://www.who.int/gender/documents/engpolicy.pdf

Zelek B, Phillips SP, Lefebvre Y. 1997. Gender sensitivity in medical curricula. Can Med Assoc J 156(9):1297-1300.

Zimmerman MK, Hill SA. 2000. Reforming gendered health care: An assessment of change. Women, health, and health care. Int J Health Serv 30(4):771-795. 